Allisson José Fernandes de Andrade, Giselle Schmidt Alves Díaz Merino, Eugenio Andrés Díaz Merino, Franciele Forcelini, Ricardo Triska *

\title{
Design Centrado no Usuário: Uso do User-Capacity Toolkit na obtenção de dados de sujeito com Artrite Reumatoide
}

Allisson José Fernandes de Andrade é Mestrando pelo programa de Pós-Graduação em Design da Universidade Federal de Santa Catarina (UFSC). Pesquisador bolsista CAPES na linha Gestão de Design. Bacharel em Design pela Universidade Federal da Paraíba (UFPB), com período sanduíche na UFSC. Tem experiência em Gestão de Design, Design Universal, Design Inclusivo, Tecnologia Assistiva, Realidade Aumentada, Usabilidade e Ergonomia. <allisson502@gmail.com> ORCID: 0000-0003-0242-0394
Resumo A Artrite Reumatoide (AR) é uma doença crônica de origem autoimune, que atinge em sua maioria mulheres de 40 a 70 anos de idade. Pensando no bem-estar e qualidade de vida dessa população, e na busca pela satisfação das necessidades humanas, a pesquisa em questão possui o objetivo de levantar as capacidades/limitações físicas e cognitivas de um sujeito com AR por meio do User-Capacity Toolkit (UCT). Este conjunto de ferramentas visa guiar as etapas de levantamento, organização e análise de dados em projetos de Tecnologia Assistiva (TA). Os resultados demonstram que as principais limitações do sujeito estão relacionadas a realização de atividades simples da vida diária, devido à redução da força e destreza causadas pela AR. Essas dificuldades reduzem a autonomia do sujeito, que acaba necessitando do auxílio de outra pessoa. Contudo, torna-se evidente a necessidade de TAs que possam reduzir essa dependência, possibilitando autonomia, conforto e segurança ao usuário.

Palavras chave Tecnologia Assistiva, Design centrado no usuário, User-Capacity Toolkit, Artrite reumatoide. 
Giselle Schmidt Alves Díaz Merino é professora do Programa de Pós-graduação em Design (UFSC) e Departamento de Design (UDESC). Doutora em Engenharia de Produção - Produto e Processo (metodologias de Design) (UFSC), Pós Doutora em Design - Fatores Humanos (UDESC) Pesquisadora CNPq - PQ2. Áreas de concentração: Design; Gestão de Design; Projeto Centrado no Ser Humano; Tecnologia Assistiva. <gisellemerino@gmail.com > ORCID: 0000-0003-4085-3561

Eugenio Andrés Díaz Merino é professor do Programa de Pós-graduação em Design e Programa de Pós-graduação em Engenharia de Produção (UFSC). Doutor em Engenharia de Produção - Ergonomia (UFSC). Pesquisador CNPq - PQ $1^{\text {a }}$. Coordenador Adjunto da área de Arquitetura, Urbanismo e Design - CAPES. Áreas de concentração: Design; Gestão de Design; Engenharia; Ergonomia; Usabilidade; Produto e Processo. <eugenio.merino@ufsc.br> ORCID: 0000-0002-7113-6031

Franciele Forcelini é designer e pesquisadora em nível de doutorado no programa de Pós-graduação em Design da Universidade Federal de Santa Catarina (UFSC). Pesquisadora do Núcleo de Gestão de Design e Laboratório de Design e Usabilidade (NGD/LDU). Membro da Rede de Pesquisa e Desenvolvimento em Tecnologia Assistiva - RPDTA. Mestra em Design (UFSC). Áreas de concentração: Design de Produto e Serviço, Gestão de Design, Ergonomia e Design Inclusivo. $<$ Franciele Forcelini> ORCID: 0000-0002-8301-201X

\section{User-Centered Design: Use of the User-Capacity Toolkit to Obtain Subject Data with Rheumatoid Arthritis}

Abstract Rheumatoid Arthritis (RA) is a chronic disease of autoimmune origin, which mostly affects women aged 40 to 70 years. Thinking about the well-being and quality of life of this population, and the search for the satisfaction of human needs, the research aims to raise the physical and cognitive abilities / limitations of a subject with RA through the User-Capacity Toolkit (UCT). This set of tools aims to guide the stages of data collection, organization and analysis in Assistive Technology (AT) projects. The results demonstrate that the main limitations of the subject are related to the performance of simple activities of daily living, as well as to the handling of the product in question, due to its limitations of strength and dexterity caused by RA. These difficulties reduce the subject's autonomy, who ends up needing the help of another person. However, it becomes evident the need for ATs that can reduce this dependency, allowing autonomy, comfort and safety for the user.

Keywords Assistive Technology, User-Centered Design, User-Capacity Toolkit, Rheumatoid Arthritis.

\section{Diseño centrado en el usuario: uso del kit de herramientas de capacidad del usuario para obtener datos de sujetos con artritis reumatoide}

Resumen La Artritis Reumatoide (AR) es una enfermedad crónica de origen autoinmune, que afecta mayoritariamente a mujeres de 40 a 70 años. Pensando en el bienestar y la calidad de vida de esta población, y en la búsqueda de la satisfacción de las necesidades humanas, la investigación en cuestión tiene como objetivo plantear las habilidades / limitaciones físicas y cognitivas de un sujeto con AR a través del User-Capacity Toolkit (UCT). Este conjunto de herramientas tiene como objetivo orientar las etapas de recopilación, organización y análisis de datos en proyectos de tecnología de asistencia (AT). Los resultados demuestran que las principales limitaciones del sujeto están relacionadas con la realización de actividades simples de la vida diaria, debido a la reducción de la fuerza y destreza provocada por la AR. Estas dificultades reducen la autonomía del sujeto, que acaba necesitando la ayuda de otra persona. Sin embargo, se hace evidente la necesidad de ED que reduzcan esta dependencia, permitiendo autonomía, comodidad y seguridad para el usuario.

Palabras clave Tecnología de Asistencia, Diseño centrado en el usuario, User-Capacity Toolkit, Artritis Reumatoide. 


\section{Introdução}

Ricardo Triska é Professor do Programa de Pós-graduação em Design (UFSC). Doutor em Engenharia de Produção (Área de concentração Ergonomia) (UFSC). Pesquisador CNPq - PQ2. Atuou como Professor Visitante na School of Art + Design da Universidade de Illinois (University of Illinois at Urbana - Champaign). Áreas de atuação: Linguagem Subliminar, Processos Corporativos, Design de Interface e Design da Informação. <ricardo.triska@ufsc.br> ORCID: 0000-0002-2822-7050
Segundo a Organização das Nações Unidas (ONU, 2019), os dados da World Population Prospects indicam que até o ano de 2050 uma em cada seis pessoas no mundo terá mais de 65 anos (16\%), demonstrando uma expectativa de que o número de pessoas com mais de 80 anos suba para cerca de 426 milhões em 2050. Acompanhando essa tendência mundial, o Instituto Brasileiro de Geografia Estatística - IBGE (2018) indica que, no Brasil, o número de pessoas com 65 anos ou mais passará de 19,2 milhões em 2018, para 58,2 milhões em 2060.

O processo de envelhecimento geralmente vem acompanhado pela dor, e em muitos casos, a crônica é a maior causa de queixas, podendo interferir no modo de vida dos indivíduos (DELLAROZA; PIMENTA; MATSUO, 2007). Esse tipo de dor dura mais que um período normal de uma lesão ou encontra-se associada à processos patológicos crônicos, que causam um processo contínuo e recorrente em intervalos de meses ou anos (SANTOS et al., 2015; DELLAROZA; PIMENTA; MATSUO, 2007). Além disso, a dor crônica tem prevalência maior em idosos (SANTOS et al., 2015) e pode estar associada a diversas doenças, entre elas, a Artrite Reumatoide (AR).

A Artrite Reumatoide é uma desordem crônica e sistêmica, que acomete com mais frequência as pequenas articulações como as das mãos e dos punhos, podendo causar deformidades que comprometem as funções manuais do sujeito (SILVA; MASSA, 2015). É um dos principais problemas causados pela doença, que predomina em mulheres de 40 a 70 anos (LEE; WEINBLAT, 2001). Sujeitos com AR costumam relatar dores nas mãos e nos pés, assim como dificuldades para ficar de pé, andar, caminhar, ou realizar algumas atividades práticas (SOCIEDADE BRASILEIRA DE REUMATOLOGIA, 2018).

Para a redução dos sintomas, além de tratamentos medicamentosos, podem ser utilizadas adaptações ou dispositivos assistivos que auxiliam o paciente com AR nas atividades cotidianas (PAULA, 2017; SANTOS et al., 2018), chamados de Tecnologias Assistivas (TAs). Elas compreendem produtos, recursos, estratégias, práticas, processos, métodos e serviços com a finalidade de promover a funcionalidade de indivíduos com deficiência ou mobilidade reduzida, visando sua autonomia, independência, qualidade de vida e inclusão social (BRASIL, 2015).

Diante do exposto, considerando o papel fundamental da TA para o bem-estar e autonomia de sujeitos com limitações, esta pesquisa tem como objetivo levantar as capacidades/limitações físicas e cognitivas de um sujeito com AR por meio da aplicação do User-Capacity Toolkit (UCT). O UCT (PICHLER, 2018) contempla um conjunto de ferramentas que visam obter dados objetivos e subjetivos, para identificação e detalhamento das capacidades e limitações físicas e/ou cognitivas de um sujeito, auxiliando em projetos de Tecnologia Assistiva. 
Deste modo, esta pesquisa apresenta uma abordagem centrada no usuário, considerando suas características individuais em todo processo. De acordo com Scherer et al. (2017), o Design Centrado no Usuário (DCU) (ou pessoa/humano) é um processo de obtenção de dados por meio de análises, pesquisas, observações, entre outros, com o objetivo de satisfazer as necessidades do usuário, inclusive por meio do projeto de produtos/serviços. Ou seja, projetos centrados nos usuários com AR devem considerar suas limitações para possibilitar projetos mais adequados (FORCELINI et al., 2018).

\section{Procedimentos metodológicos}

Esta pesquisa possui: (1) natureza aplicada, visando gerar informações para a solução de problemas específicos - uso prático; (2) abordagem qualitativa, considerando o sujeito e o mundo real, onde ocorre a interpretação dos fenômenos (SILVA; MENEZES, 2005) e; (3) objetivo exploratório, que almeja a familiarização com o problema, o aprimoramento de ideias ou a descoberta (GIL, 2002). Desta forma, por meio da aplicação do User-Capacity Toolkit (UCT), esta pesquisa buscou levantar as características físicas e cognitivas de um sujeito com AR, aproximando a equipe de projetos de suas capacidades e limitações, o que pode auxiliar no processo de desenvolvimento de um projeto de TA.

\section{Materiais e métodos}

Esta pesquisa foi desenvolvida por meio de três etapas: (1) Seleção da amostra de sujeitos e produto para teste; (2) Levantamento de dados e (3) Organização e análise dos dados.

Na Etapa 1, de Seleção da amostra de sujeitos foi realizada por meio de uma entrevista preliminar com o grupo de pessoas com Artrite Reumatoide (Artrativa) da Universidade do Estado de Santa Catarina (UDESC), avaliando-se os seguintes critérios de inclusão: (1) diagnóstico de AR; (2) estilo de vida ativo; (3) estágio da doença moderado; (4) boa capacidade de comunicação com a equipe de projeto e; (5) disponibilidade para participar das coletas de dados. Sendo assim, foi possível identificar um único sujeito em potencial para a realização do levantamento de dados, o que se justifica pela exclusão de possíveis participantes que não se enquadraram nos critérios de inclusão. Da mesma forma, a Seleção do produto para teste foi baseada na entrevista preliminar com o grupo Artrativa, onde foi possível identificar extrema dificuldade no uso de abridores de latas comuns.

A Etapa 2, de Levantamento de dados, contemplou o levantamento bibliográfico dentro das áreas de interesse, que incluiu artigos, sites e periódicos nacionais e internacionais. Posteriormente, foram realizadas as 
coletas objetivas e subjetivas por meio do UCT (Figura 1), o qual contempla um conjunto de ferramentas que visam guiar as equipes de projeto nas etapas de levantamento, organização e análise de dados em projetos de Tecnologia Assistiva. É composto por um Manual de Instruções; um Guia de Coleta de Dados Subjetivos; um Guia de Coleta de Dados Objetivos; um Guia de Conversão, que auxilia a equipe na conversão dos dados em informações relevantes ao projeto; e Painéis de Síntese Visual, que possibilitam melhor visualização dos dados obtidos para discussão entre a equipe (PICHLER, 2018).

Fig 1. Esquematização do User-Capacity

Toolkit | Fonte: Pichler (2018)
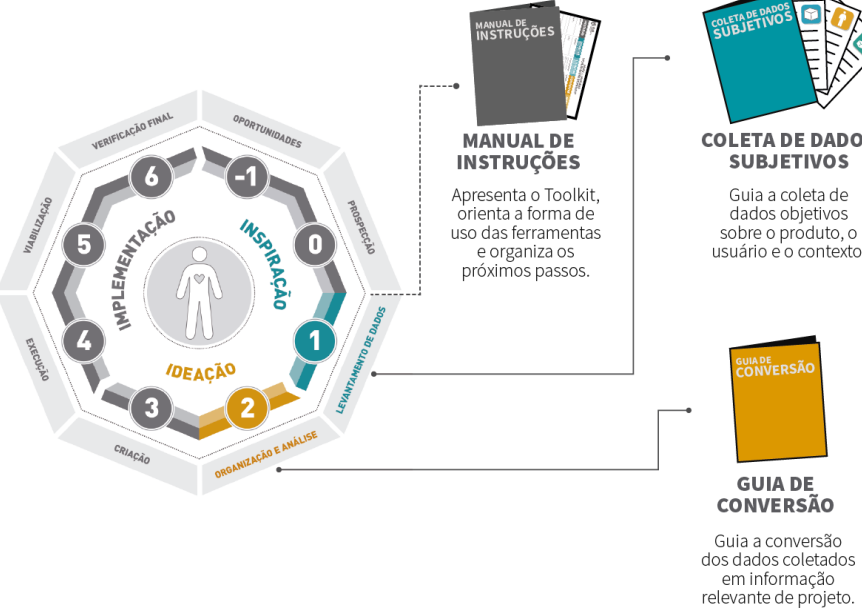

Guia a conversão dos dados coletados eminformaçãa
relevante de projeto
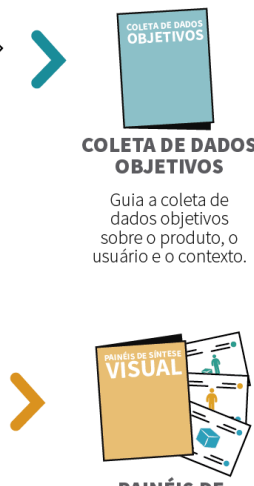

PAINÉIS DE SÍNTESE VISUAL Permite a visualização convertidas e na
discussão em equipe.

Os procedimentos de coletas de dados com o sujeito da pesquisa aconteceram no Centro de Ciências da Saúde e Desportos - CEFID (UDESC), no dia 02 de agosto de 2018. Para tanto, o sujeito participante foi informado sobre os objetivos da pesquisa e consentiu em participar da mesma por meio da assinatura do Termo de Consentimento Livre e Esclarecido (TCLE) e do Termo de Consentimento para Uso de Imagem e Voz (TCUIV). Todas as coletas realizadas foram contempladas por um projeto aprovado pelo Comitê de Ética, sob o parecer de número 2.732.152.

Os levantamentos com o UCT contemplaram coletas de dados subjetivos e objetivos. Os dados subjetivos foram coletados com o auxílio do Guia de Coleta de Dados Subjetivos (PICHLER, 2018), que orientou o levantamento de dados com o sujeito por meio de três blocos de perguntas, sobre Produto, Usuário e Contexto. 
- No bloco de Produto foram realizadas perguntas em relação a: (1) Função Prática - Facilidade de Uso, Advertência, Materiais, Força e Dimensões; (2) Função Estética - Agradabilidade e Adaptabilidade; e (3) Função Simbólica - Comunicação, Sensações e Experiência.

- No bloco de Usuário, as questões relacionavam-se aos aspectos: (1) Sensorial-Ver, Ouvir, Falar, Tocar e Sentir; (2) Cognitivo - Intelectual, Consciência, Orientação, Controle, Memória, Atenção e Pensamento; (3) Motor - Músculos, Articulação, Ossos, Ligamentos, Curvar, Alcançar, Erguer/Carregar, Girar o pescoço, Sentar/ Levantar, Equilíbrio, Manusear e Caminhar.

- No bloco de Contexto: foram realizadas perguntas em relação a: (1) Relacionamentos - Manuseio, Manutenção, Limpeza e Montagem; (2) Ambiente Condição Climática, Condição Luminosa, Condição Acústica, Vibração, Agentes Químicos, Limpeza, Trânsito no Espaço, Apoios/Suportes e Acesso; e (3) Atividades - Lavar, Cuidar, Arrumar, Preparar, Comprar, Comer, Vestir e Conduzir.

A coleta de dados objetivos, por sua vez, se utilizou do Guia de Coleta de Dados Objetivos (PICHLER, 2018), que orientou o uso das seguintes ferramentas e instrumentos tecnológicos:

- Medida de Emoção do Usuário: originalmente desenvolvida por Pieter Desmet, essa ferramenta recebe o nome de PrEmo (Product Emotion Measure) e tem como objetivo medir a emoção do usuário por meio de sete expressões faciais positivas e sete negativas A partir do PrEmo, Araújo et al. (2015) desenvolveram uma versão adaptada para Pessoa Com Deficiência (Cartela PrEmo adaptado), contendo as mesmas 14 emoções representadas por uma pessoa idosa (PICHLER, 2018).

- Escala de Avaliação de Dor FACES ${ }^{\oplus}$ foi desenvolvida por Donna Wong e Connie Baker em 1983, inicialmente visando ajudar crianças a se comunicarem em relação ao seu nível de dor. Atualmente a ferramenta é considerada a mais consolidada na área da saúde e utilizada com os mais diversos públicos. Seu objetivo é mensurar por meio de seis rostos (desenhos), o nível de dor do paciente (auto avaliação), em uma escala que vai de 0 (nenhuma dor) a 10 (dor máxima). Para Pichler (2018), essa escala pode ser utilizada no UCT tanto no 
item "Sentir", quanto no item "Motor", mensurando o grau de dor do usuário.

- Dinamômetro: segundo Dias et al. (2010, p.20), "é um equipamento que permitem a mensuração da força aplicada". É utilizado para medir a Força de Preensão Manual (FPM), estão relacionados à intensidade de contração, tempo de duração da contração e ao número de repetições realizadas. Para Pichler (2018), o Dinamômetro de Preensão Palmar pode ser utilizado como uma alternativa para medir a capacidade de força aplicada e a resistência do usuário em tempo real, sendo bastante utilizado na área da saúde e esporte. 0 equipamento utilizado nesta pesquisa foi o Dinamômetro de Preensão Palmar da marca Sehan ${ }^{\circledR}$, disponibilizado pelo Núcleo de Gestão de Design e Laboratório de Design e Usabilidade (NGD-LDU), que seguiu os critérios da Sociedade Americana de Terapeutas da Mão (BAHANNON, 2001).

- Câmera Termográfica: instrumento utilizado para mensurar a temperatura superficial de um corpo. É considerado um método não invasivo e seguro, com o objetivo de identificar por meio do fluxo sanguíneo, as regiões corporais mais acometidas por lesões (PICHLER, 2018; FORCELINI et al., 2018). Para essa coleta foi utilizada a câmera termográfica Flir ${ }^{\circledast}$ E40 e para as medições ambientais o TermoHigro-Anemômetro THAL 300, da Instrutherm ${ }^{\circledast}$. A temperatura do ambiente permaneceu em $28^{\circ} \mathrm{C}$, a umidade do ar em $55 \%$ e a velocidade do ar em $0 \mathrm{~m} / \mathrm{s}$. O sujeito passou por um período de aclimatização de 15 minutos, conforme sugere Alves Neto et al. (2009) e, posteriormente, foram realizados dois registros: (1) um registro do sujeito em repouso e; (2) um registro após o uso do abridor de latas analisado.

Por fim, a Etapa 3 contemplou a Organização e análise dos dados, utilizando-se do Guia de Conversão do UCT, que permitiu a segmentação dos dados obtidos de acordo com o grau de capacidade e limitações do sujeito. Para esta classificação, foram utilizadas as cores propostas pelo UCT: (1) verde para positivo; (2) amarelo para intermediário e; (3) vermelho para negativo. Desta forma, os dados foram organizados por meio de post-its, criando Painéis de Síntese Visual (Produto, Usuário e Contexto), que possibilitam melhor visualização dos dados obtidos para discussão entre a equipe (PICHLER, 2018). 
Design Centrado no Usuário: Uso do User-Capacity Toolkit na obtenção de

\section{Referencial teórico}
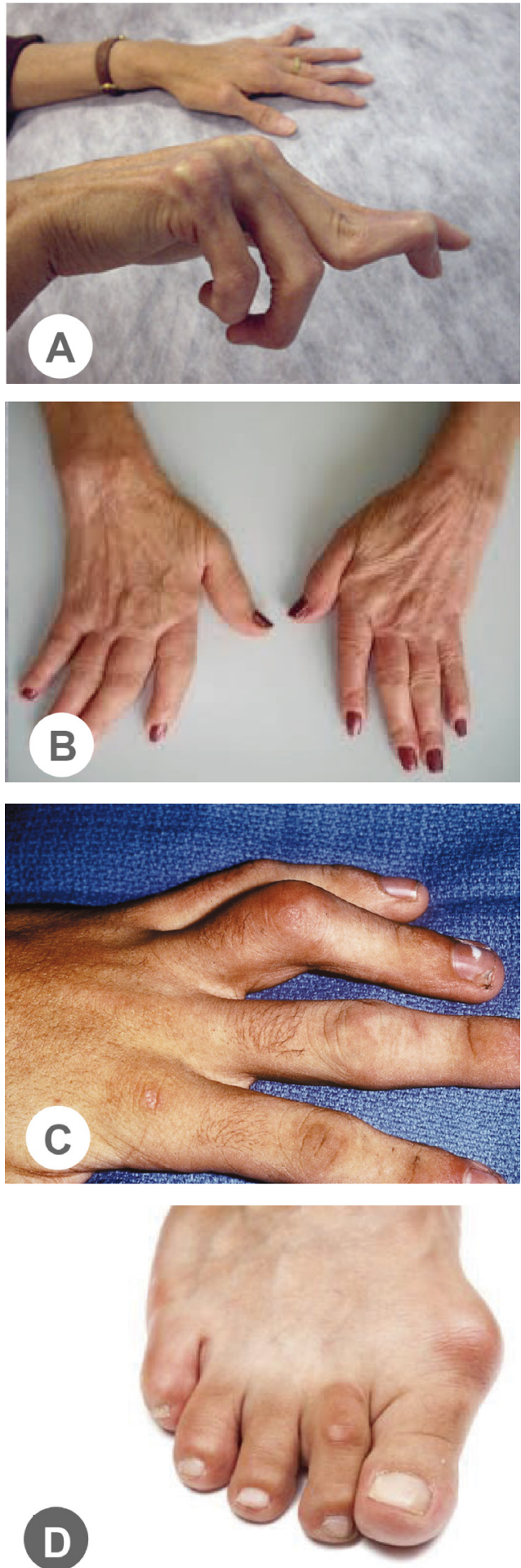

Fig 2. Deformidades nas articulações periféricas - AR | Fonte: elaborado com base em Kontzias (2020).
O levantamento bibliográfico realizado para embasar esta pesquisa contemplou os seguintes temas: Artrite Reumatoide (AR); Tecnologia Assistiva (TA) e; Design Centrado no Usuário (DCU).

\section{Artrite Reumatoide}

A Artrite Reumatoide (AR) é uma doença sistêmica e autoimune, marcada pela sinovite crônica que acarreta progressivos danos e perdas de função (SILVAGNI, 2020). É caracterizada pela persistente inflamação das articulações afetadas, que resulta em seu comprometimento, assim como erosões ósseas e incapacidades (SMOLEN; ALETAHA; MCINNES, 2016). No início, a AR afeta apenas algumas articulações, mas em estágios posteriores atinge diversas outras, além de provocar sintomas extra articulares (LIN; ANZAGHE; SCHÜLKE, 2020).

A AR é uma das doenças inflamatórias crônicas mais prevalecentes (SMOLEN; ALETAHA; MCINNES, 2016). Acomete cerca de 0,4\% a 1\% da população mundial, atingindo com mais frequência pessoas na média dos 60 anos, sendo três vezes mais comum em mulheres do que em homens (LITTLEJOHN; MONRAD, 2018; MYASOEDOVA et al, 2010; SACKS; LUO; HELMICK, 2010). No Brasil a doença acomete cerca de $0,2 \%$ a $1 \%$ da população, estimando-se em 1,3 milhão de pessoas acometidas pela doença (COSTA et al., 2014). Se considerada a faixa etária de 55 a 74 anos, a prevalência da AR no Brasil sobe para 0,3\% a 2,7\% (SENNA et al., 2004).

A Artrite Reumatoide se faz bastante presente nos membros superiores, gerando problemas diretamente relacionados a capacidade e independência do sujeito, causados pelas complicações articulares (SILVA; MASSA, 2015). As articulações periféricas são as mais comuns de serem acometidas por essas deformidades (Figura 2), como os dedos em pescoço de cisne (Figura $2-\mathrm{A}$ ), desvio ulnar (Figura $2-\mathrm{B}$ ), dedos em botoeira (Figura 2 - C) e hálux valgo, comumente conhecido como joanete (Figura 2 - D) (SOCIEDADE BRASILEIRA DE REUMATOLOGIA, 2018).

Segundo Mota et al. (2013), na fase inicial da doença as manifestações articulares podem ser reversíveis, contudo, se a inflamação não for controlada pode acarretar destruição óssea e cartilaginosa, lesões tendinosas e ligamentares irreversíveis. Goeldner et al. (2011) afirmam que cerca de $50 \%$ dos pacientes acometidos também sofrem manifestações extra articulares, como a síndrome de Sjögren (doença autoimune que provoca inflamação de órgãos e glândulas) e os nódulos reumatoides, provocando inflamação dos vasos sanguíneos, que resultam em necrose. 


\section{Tecnologia Assistiva}

A Pesquisa Nacional de Saúde - PNS (2015), realizada pelo IBGE, destaca que aproximadamente $6,2 \%$ da população brasileira possui algum tipo de deficiência, dos quais cerca de $0,3 \%$ nasceu com alguma deficiência física, enquanto $1,0 \%$ a adquiriu durante a vida, devido a alguma doença ou acidente. No entanto, cabe ressaltar que essa aquisição de uma deficiência pode trazer impactos significativos na vida de um indivíduo, promovendo diversas transformações em sua realidade (LOPES, 2014).

Uma dessas transformações pode ser a necessidade de um dispositivo ou tecnologia assistiva (TA). As TAs compreendem produtos, recursos, estratégias, práticas, processos, métodos e serviços com a finalidade de promover a funcionalidade de indivíduos com deficiência ou mobilidade reduzida, visando sua autonomia, independência, qualidade de vida e inclusão social (BRASIL, 2015). Caracterizam-se como uma forma de promoção de recursos que proporcionam a execução de atividades de maneira normal por pessoas que possuem algum tipo de deficiência ou idade mais avançada e, que por esse motivo, encontram dificuldades na realização de determinadas atividades (BERSCH, 2013).

De acordo com Pinto et al. (2016), para um indivíduo cuidar de si mesmo e viver de maneira independente, é necessário que este tenha capacidade para realizar diversas tarefas. As Atividades da Vida Diária (AVD's) representam uma ampla gama de atividades que um indivíduo realiza, que vão desde procedimentos simples de autocuidado, até atividades mais complexas como a realização de esportes (RIBEIRO; NERI, 2012). Ou seja, as AVD's exigem certa autonomia e independência do indivíduo e podem ser comprometidas por doenças como a AR, evidenciando a necessidade do desenvolvimento de TAs para melhoria da qualidade de vida desses individuos.

O principal objetivo das TAs é proporcionar independência e autonomia para as pessoas com deficiência ou mobilidade reduzida, para que haja a ampliação de sua mobilidade, comunicação, habilidades, entre outros (BERSCH, 2013; BRASIL, 2015). De acordo com o Comitê de Ajudas Técnicas (BRASIL, 2009), a TA não se limita à produtos que auxiliam na função, pois envolve uma série de aspectos como serviços, estratégias, práticas e, acima de tudo, a aplicação do conhecimento.

Um estudo multicêntrico realizado por De Boer et al. (2009) em hospitais na Holanda, entrevistou 240 pessoas com AR, das quais 213 (89\%) utilizava um ou mais dispositivos assistivos. Entretanto, segundo o estudo, as proporções de pessoas que nunca fazem uso de seus dispositivos, variou entre $8 \%$ para palmilhas ortopédicas e $23 \%$ para barras de apoio. Segundo o estudo, a razão comum para o abandono das TAs, são o comprometimento, incapacidade, insatisfação com o dispositivo ou autoeficácia. 


\section{Design Centrado no Usuário}

Segundo Fabrício et al. (2015, p. 74), o principal aspecto do Design Centrado no Usuário (DCU) “[...] está no envolvimento efetivo dos usuários finais no processo de design e na maneira como eles influenciam na forma do projeto". Ainda segundo os autores, o DCU é um conjunto de métodos que propõem o desenvolvimento de artefatos colocando o ser humano como figura principal, mas além disso, levando sempre em consideração as suas características para desenvolver o resultado final. Para Kalbach (2009, p. 38) o DCU “[...] consiste de metodologias que tornam o usuário uma parte integral do processo de desenvolvimento, com atividades como entrevistas, observações e vários tipos de testes".

As etapas do processo de uma metodologia centrada no usuário contribuem para reduzir os erros e melhorar os resultados, de maneira a tornar mais eficientes os recursos intelectuais e/ou financeiros de um projeto (SCHERER et al., 2017). No DCU, pesquisas e entrevistas auxiliam o projetista na melhor compreensão sobre a vida do indivíduo, o que pode resultar na descoberta de necessidades e experiências subjacentes, úteis para o desenvolvimento de um potencial produto (OZENC, 2014).

$O$ estudo de Harada et al. (2016) revela que as pesquisas que se utilizam de usuários reais, possuem melhores resultados do que as que fazem uso de "personas". Segundo os autores, a experiência e comprometimento dos projetistas não devem se sobressair às informações que os usuários têm a oferecer, como suas experiências e limitações. Para Kalbach (2009), as metodologias centradas no usuário dispensam adivinhações sobre os usuários, fazendo suposições com base em dados realísticos.

Diante do exposto, entende-se que as pessoas acometidas pela Artrite Reumatoide podem ter diversas capacidades comprometidas, as quais geram dificuldades e limitações na realização de atividades da vida diária. Essas condições evidenciam a necessidade de recursos auxiliares como as tecnologias assistivas, as quais devem ser centradas nas especificidades dos usuários, aumentando sua autonomia, inclusão e qualidade de vida. 


\section{Resultados}

A primeira etapa desta pesquisa contemplou a Seleção da amostra de sujeitos e produto para teste. Desta forma, devido aos critérios de inclusão definidos, foi selecionada uma única participante do sexo feminino, com 52 anos, $1,53 \mathrm{~m}$ de altura, $58 \mathrm{~kg}$, a qual foi diagnosticada com Artrite Reumatoide aos 46 anos de idade por um Reumatologista. A participante (sujeito da pesquisa) considera-se independente, foi professora de ginástica, mas atualmente atua como Personal Trainer. Possui alteração na pressão sanguínea, alergia respiratória e a mão direita como dominante. 0 produto definido para o teste foi o abridor de latas comum, descrito como um produto de extrema dificuldade para uso com as condições da AR.

Definido o sujeito e produto para teste, foi realizada a Etapa 2, que compreendeu o Levantamento de dados subjetivos e objetivos por meio do UCT. A Coleta Subjetiva contemplou perguntas sobre o produto (abridor de latas comum), o usuário (sujeito da pesquisa) e contexto de uso do produto (cozinha). Já as Coletas Objetivas (Figura 3) com as ferramentas de Medição da Emoção do Usuário (Sensações), Escala de Avaliação de Dor (Sentir e Motor) permitiram a compreensão das sensações do sujeito em relação ao uso do produto e suas dores. 0 dinamômetro permitiu a medição da força e a termografia possibilitou verificar as áreas com alteração térmicas.

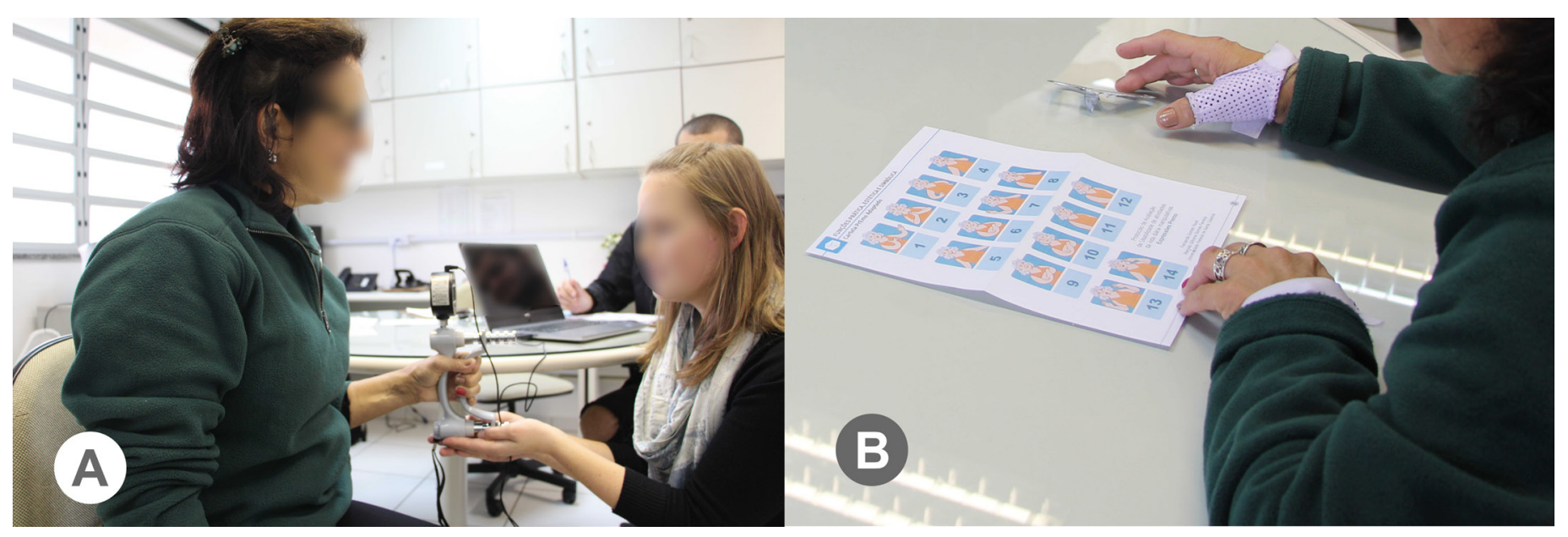

Fig 3. (A) Uso do Dinamômetro e (B) Uso da ferramenta Emoção do Usuário Fonte: os autores.

$\mathrm{Na}$ Etapa 3, de Organização e análise dos dados, os dados obtidos foram analisados e convertidos em Painéis Visuais de Produto, Usuário e Contexto, a partir do Guia de Conversão do UCT. Com base nas observações da equipe e relatos do próprio sujeito, as informações coletadas foram classificadas em positivas (identificadas pela cor verde), intermediárias (identificadas pela cor amarela) e negativas (identificadas pela cor vermelha).

No primeiro painel obtido - Painel do Produto (Figura 4) - foram obtidas as seguintes informações, classificadas em intermediárias e negativas: 


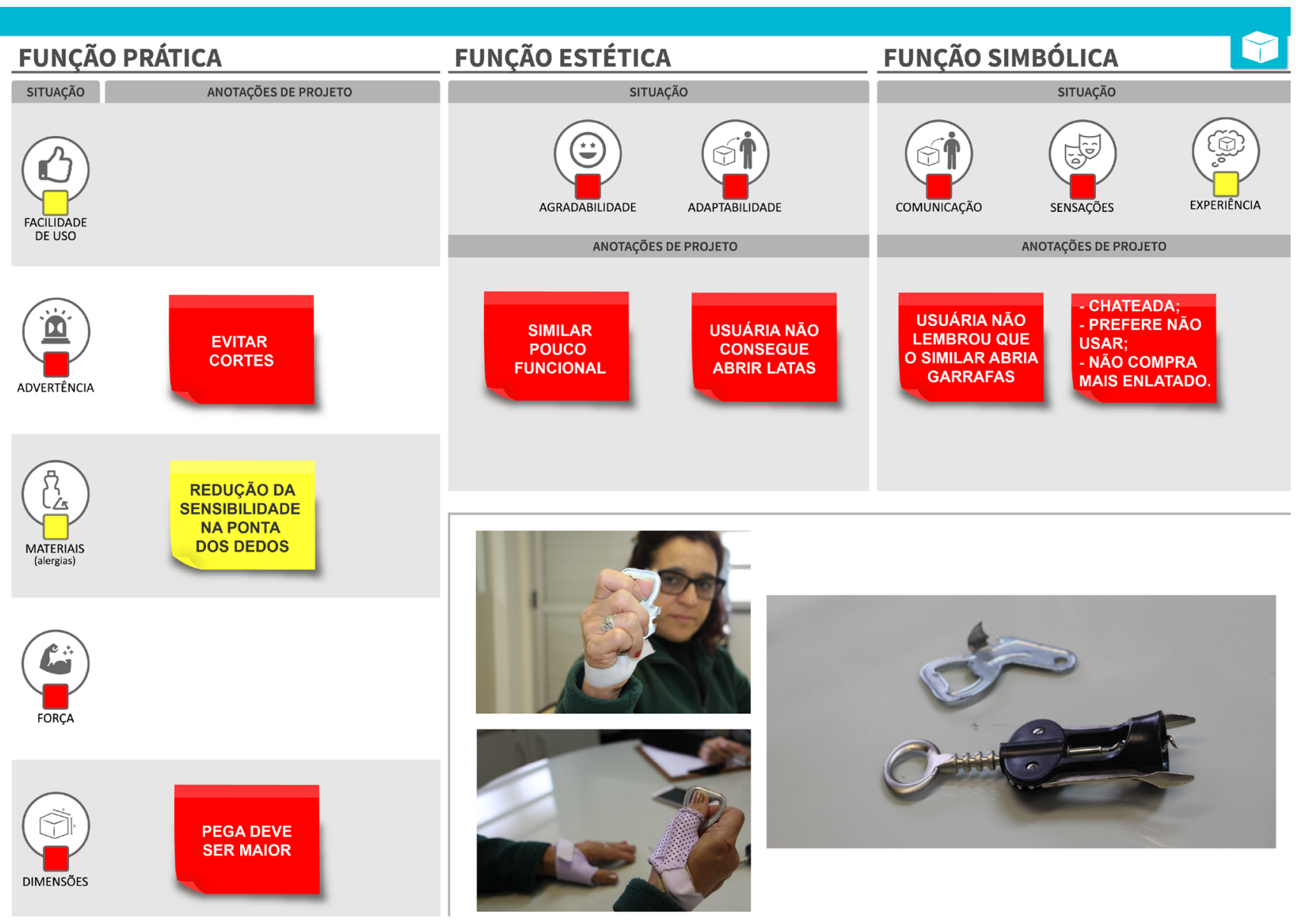

Fig 4. (Painel de Síntese Visual - Produto. | Fonte: elaborado com base em Pichler (2018).

Obtiveram classificação amarela (aspectos intermediários):

- Facilidade de uso - o sujeito afirmou ter pouca experiência com o abridor de latas e o uso é eventual;

- Experiência - sujeito relatou que certa vez tentou abrir uma lata de extrato de tomate, mas não conseguiu finalizar a ação;

- Materiais - sujeito afirmou que o abridor de latas é de difícil limpeza, desconfortável e inseguro (o sujeito apresenta redução da sensibilidade na ponta dos dedos).

Já a classificação vermelha (aspectos negativos) foi direcionada a:

- Advertência - sujeito relatou danos moderados causados pelo uso do abridor anteriormente (segundo ele, um possível novo produto deve evitar cortes);

- Força - sujeito relatou que o abridor exige muita força e por esse motivo não consegue realizar a atividade de abrir a lata; 
- Dimensões - para o sujeito as dimensões são inadequadas em alguns aspectos (para ele, a pega deveria ser maior);

- Agradabilidade - para o sujeito, o abridor é pouco funcional;

- Adaptabilidade - sujeito relatou que não consegue abrir latas;

- Comunicação - segundo o sujeito, o produto é confuso e não permite a compreensão do seu funcionamento (o sujeito não lembrou em um primeiro momento, que o produto similar também abre garrafas);

- Sensações - segundo o sujeito, o produto a deixa chateada e, por este motivo, prefere não usá-lo. Além disso, afirmou que não compra mais produtos enlatados. $\mathrm{Na}$ Coleta Objetiva com a ferramenta Medida de Emoção do Usuário, os resultados foram: (9) Insatisfação e (10) Desprezo.

Fig 5. Painel de Síntese Visual - Usuário. Fonte: elaborado com base em Pichler (2018).
No Painel do Usuário (Figura 5), foram obtidas as seguintes informações, classificadas em positivas, intermediárias e negativas:

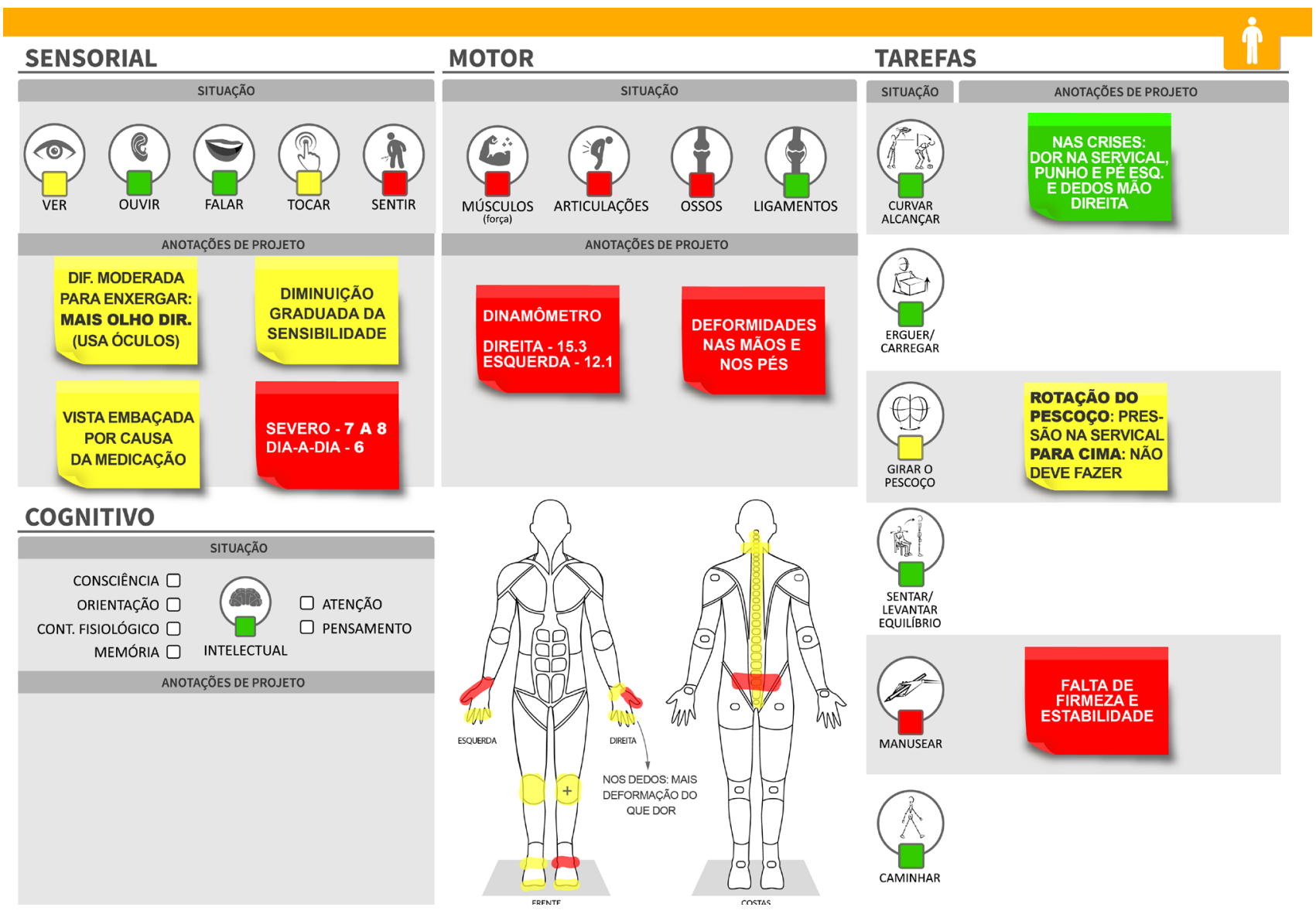


Obtiveram classificação verde (aspectos positivos):

- Ouvir - mediante observação, esse aspecto foi considerado normal;

- Falar - mediante observação, foi considerado normal;

- Ligamentos-foi observado que o sujeito não apresenta comprometimento que afete o uso do abridor;

- Curvar/Alcançar - sujeito conseguiu realizar a ação solicitada normalmente, mas nas crises afirma ter dor na cervical, pé, punho e dedos das mãos;

- Erguer/Carregar - sujeito carregou o objeto solicitado sem dificuldade;

- Sentar/Levantar - sujeito manteve o equilíbrio com facilidade e sem apoios durante a ação solicitada;

- Caminhar - sujeito caminhou com facilidade e estabilidade durante a ação solicitada.

Obtiveram classificação amarela (aspectos intermediários):

- Ver - sujeito possui dificuldade moderada para enxergar, usa óculos e afirma que "às vezes a vista embaça" por causa da medicação;

- Tocar - sujeito apresenta diminuição gradual da sensibilidade;

- Girar o Pescoço - a rotação do pescoço causa pressão na cervical, já o movimento de hiperextensão da cabeça o sujeito afirma não poder realizar, segundo instruções médicas.

Obtiveram classificação vermelha (aspectos negativos):

- Sentir - sujeito apresentou condição de dor severa (6) na escala de dor (escala de 0 - 10) da Coleta Objetiva com a ferramenta Escala de Avaliação de Dor FACES ${ }^{\oplus}$;

- Músculos - sujeito apresentou comprometimento grave, segundo a Coleta Objetiva com o Dinamômetro, a saber: Mão direita (kg) - média 15.3; e Mão esquerda (kg) - média 12.1;

- Articulação - sujeito apresentou alteração grave, corroborada pelas alterações térmicas da imagem termográfica gerada.

- Ossos - foi observado que o sujeito apresenta deformidades nas mãos e nos pés;

- Manusear - foi observado que o sujeito apresentava falta de firmeza e estabilidade em ações de manuseio. 
O Mapa Corporal, ampliado na Figura 6, apresenta os locais de dor em partes do corpo do sujeito, obtidas com o auxílio da ferramenta Escala de Avaliação de Dor FACES ${ }^{\circledast}$ e classificadas em dor mediana (amarelo) e dor elevada (vermelho).

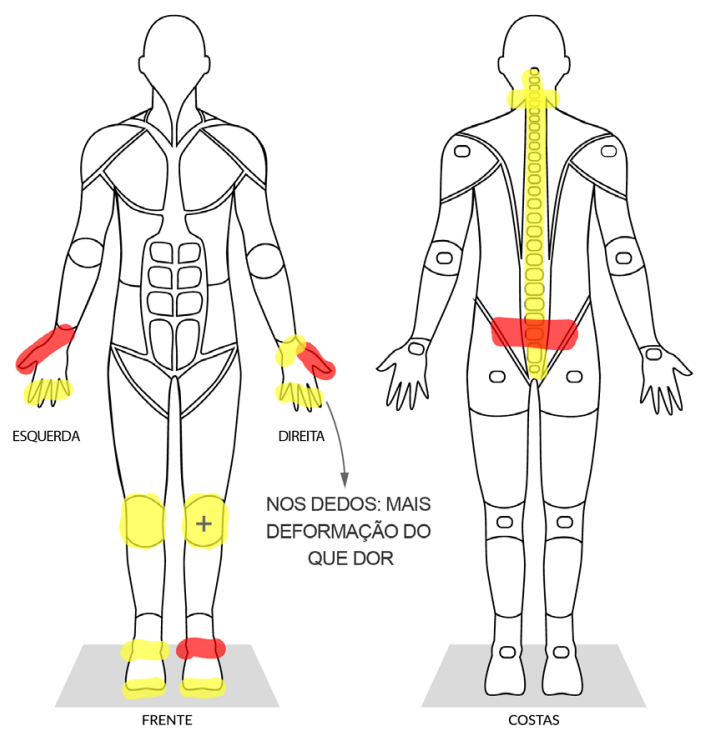

Fig 6. Mapa Corporal. | Fonte: elaborado com base em Pichler (2018).
- Na classificação amarela (dor mediana) estão: dor e deformação dos dedos de ambas as mãos (escala de dor 4); punho direito (escala de dor 6); joelhos (direito escala 6 e esquerdo escala 4); tornozelo esquerdo (escala 6) e; dedos dos pés (escala 6). 0 sujeito também relatou sentir dores nas costas por toda região da medula espinhal, e classificou na escala de dor como variante de $6-8$.

- Na classificação vermelha (dor elevada) estão: polegares de ambas as mãos (escala de dor 8); punho esquerdo (escala de dor 10); tornozelo direito (escala de dor 8) e; lombar (escala de dor 8).

Já no Painel do Contexto (Figura 7), vale salientar que não houve a presença de aspectos negativos (vermelho). Nele, obtiveram-se as seguintes informações:

Obtiveram classificação verde (aspectos positivos):

- Manuseio - sujeito afirmou que o marido (com 50 anos de idade) ajuda no manuseio;

- Manutenção - N/A;

- Montagem - N/A;

- Condição Climática - segundo o sujeito, a condição climática do ambiente é boa e o espaço bem arejado;

- Condição Luminosa - segundo o sujeito, o ambiente apresenta boa iluminação;

- Condição Acústica - boa, segundo o sujeito;

- Vibração - N/A;

- Limpeza - segundo o sujeito, o ambiente é limpo e organizado;

- Trânsito no espaço - segundo o sujeito, não há obstáculos;

- Apoios/Suportes - N/A;

- Acesso - N/A; 
- Executar - sujeito afirmou sentir dificuldades para lavar o rosto e se limpar, a escova não encaixa bem na mão, mas consegue realizar. Para ele, girar a tranca da porta é difícil;

- Organizar - sujeito afirmou conseguir arrumar a casa apenas quando não está em crise, mas evita cozinhar;

- Decidir - sujeito afirmou sentir dificuldade para vestir roupas justas e que "sente o punho";

- Conduzir - sujeito afirmou sentir dor ao dirigir, e que não consegue mais andar de bicicleta.

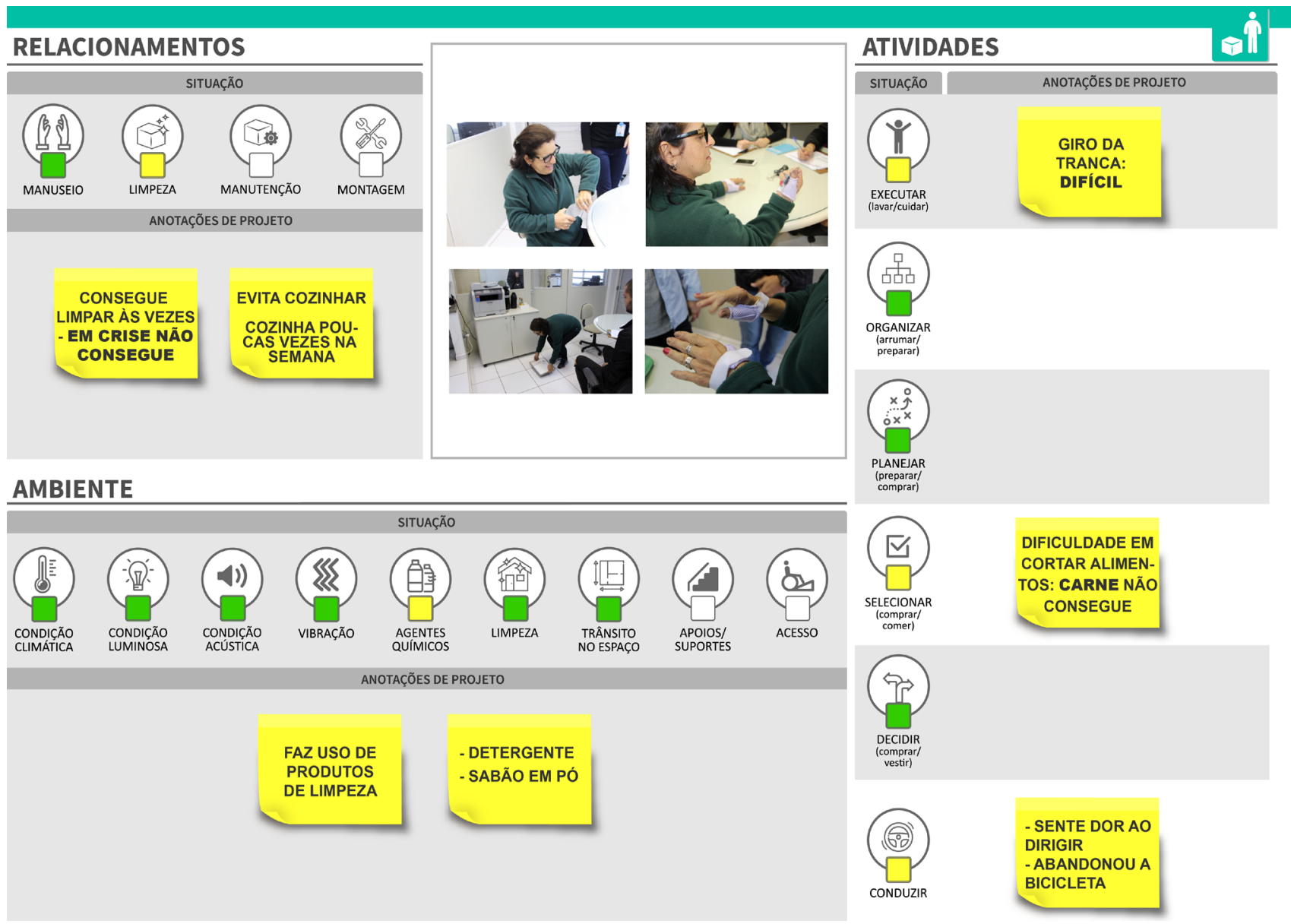

Fig 7. Painel de Síntese Visual - Contexto. | Fonte: elaborado com base em Pichler (2018).
Obtiveram classificação amarela (aspectos intermediários):

- Limpeza - sujeito afirmou realizar sozinho, mas com dificuldade;

- Agentes Químicos - sujeito afirmou ter contato com detergente, sabão em pó e amaciante;

- Planejar/Selecionar - sujeito afirmou que para realizar as compras utiliza o carrinho de supermercado, nas refeições relata que não consegue cortar carnes, e às vezes precisa do auxílio do marido. 


\section{Conclusão}

Mediante a aplicação do User-Capacity Toolkit, foi possível levantar as capacidades e limitações - físicas e cognitivas - do sujeito da pesquisa, acometido pela Artrite Reumatoide. As coletas permitiram a compreensão dos aspectos positivos, intermediários e negativos em relação ao produto (abridor de latas), ao usuário (sujeito) e ao contexto (cozinha) observados.

o produto analisado - abridor de latas - não apresentou aspectos positivos e, em contrapartida, demonstrou aspectos intermediários relacionados à facilidade de uso, à experiência e aos seus materiais, que o tornam desconfortável e inseguro. Já os negativos foram associados a advertência, força excessiva exigida, dimensões inapropriadas, pouca agradabilidade, adaptabilidade e comunicação do produto, bem como às sensações de insatisfação provocadas pela impossibilidade do seu uso.

$\mathrm{O}$ sujeito da pesquisa apresentou aspectos positivos em relação à audição, fala e aos ligamentos. De modo geral, quando não está em crise, o sujeito consegue se curvar, alcançar, erguer, carregar, sentar, levantar e caminhar sem dificuldades. Os aspectos intermediários relacionam-se a visão (afetada pela medicação), ao toque e à movimentação do pescoço. Já os negativos estão associados às sensações e dores severas, ao comprometimento grave de músculos, articulações e ossos, que afetam a sua firmeza e estabilidade durante o manuseio de objetos.

O contexto por sua vez, apresentou alguns aspectos positivos em relação aos quesitos manuseio (auxiliado pelo marido), condição climática, luminosa e acústica, apresentando boa limpeza, organização e trânsito facilitado. Em contraponto, o sujeito relatou algumas dificuldades em executar algumas atividades simples, como organizar a casa em dias de crise, cozinhar, vestir roupas justas e dirigir. Os aspectos intermediários relacionam-se a limpeza e algumas dificuldades de realizar tarefas como preparar refeições.

Esses dados demonstram que as principais limitações do sujeito estão relacionadas a realização de simples atividades da vida diária, bem como ao manuseio do produto em questão, devido as limitações de forca e destreza causadas pela AR. Essas dificuldades reduzem a autonomia do sujeito, que acaba necessitando do auxílio de outra pessoa. Sendo assim, torna-se evidente a necessidade de TAs que possam reduzir essa dependência, possibilitando autonomia, conforto e segurança ao sujeito.

Sendo assim, pode-se ressaltar que os materiais e métodos adotados permitem a compreensão das necessidades reais do sujeito, essenciais para orientar a equipe de projeto durante desenvolvimento de uma TA. As coletas orientadas pelos guias de coletas subjetivas e objetivas do UCT possibilitaram a obtenção dos dados de forma rápida e prática, possibilitando a compreensão das capacidades e limitações do sujeito. 
As coletas subjetivas permitiram a obtenção de um panorama sobre as condições do sujeito e suas percepções, considerando aspectos que possivelmente poderiam passar despercebidos. Já as objetivas, com o uso de ferramentas consolidadas e instrumentos tecnológicos, possibilitaram reforçar dados e especificidades do sujeito, tornando o processo mais confiável. Por fim, a conversão dos dados em painéis visuais propiciou melhor visualização das informações que, dessa forma, podem ser consultadas pela equipe de projeto durante todo o processo de desenvolvimento de um produto.

Como futuros estudos, pretende-se desenvolver um produto (TA) que possa ser utilizado por pessoas com necessidades similares às observadas com o sujeito da pesquisa, que demonstra comprometimentos característicos da AR. Esse produto teria como objetivo a promoção da autonomia e independência desse público. Ainda, pretende-se ampliar a amostra de sujeitos para a obtenção de um panorama mais amplo, que considere as diversas formas de manifestação da AR.

\section{Agradecimentos}

Agradecemos ao Programa de Pós-graduação em Design da UFSC, ao Núcleo de Gestão de Design e Laboratório de Design e Usabilidade (NGD-LDU/UFSC), à Rede de Pesquisa e Desenvolvimento em Tecnologia Assistiva (RPDTA), aos coordenadores e integrantes do projeto Artrativa/UDESC e ao sujeito envolvido. $O$ presente trabalho foi realizado com apoio da Coordenação de Aperfeiçoamento de Pessoal de Nível Superior - Brasil (CAPES) - Código de Financiamento 001.

\section{Referências}

ALVES NETO, O. et al. Dor: princípios e prática. Porto Alegre: Artmed, 2009.

ARAÚJO, F. S.; et al. Personalização da ferramenta PrEMO para avaliação da experiência do usuário: buscando uma maior relação com o usuário. Human Factors in Design, [s.i.], v. 4 , n. 8, p. 76-94, 2015.

BAHANNON, R. Dynamometer measurements of hend-grip strenght predict, iltiple outcomes. Perceptual and Motor Skills, v. 93, p. 323-328, 2001.

BERSCH, Rita. Introdução à tecnologia assistiva. Porto Alegre: CEDI, p. 21, 2013.

BRASIL. Lei 13.146 de 06 de julho de 2015. Institui a Lei Brasileira de Inclusão da Pessoa com Deficiência (Estatuto da Pessoa com Deficiência). Diário Oficial da União, 2015.

BRASIL. Subsecretaria Nacional de Promoção dos Direitos da Pessoa com Deficiência. Comitê de Ajudas Técnicas. Tecnologia Assistiva. - Brasília: CORDE, 2009. 138 p. 
COSTA, J. O. et al. Tratamento da artrite reumatoide no Sistema Único de Saúde, Brasil: gastos com infliximabe em comparação com medicamentos modificadores do curso da doença sintéticos, 2003 a 2006. Cad. Saúde Pública, Rio de Janeiro, vol. 30, n.2, p.283-295, fev, 2014. DE BOER, I. G. et al. Assistive devices: usage in patients with rheumatoid arthritis. Clinical rheumatology, v. 28, n. 2, p. 119-128, 2009.

DELLAROZA, Mara Solange Gomes; PIMENTA, Cibele Andrucioli de Mattos; MATSUO, Tiemi. Prevalência e caracterização da dor crônica em idosos não institucionalizados. Cadernos de saúde pública, v. 23, p. 1151-1160, 2007.

DIAS, J. A. et al. Força de preensão palmar: métodos de avaliação e fatores que influenciam a medida. Rev Bras. de Cineantropometria \& Desempenho Humano, v.12, n.3, p. 209-216, 2010. FABRÍCIO, Marcos André et al. Tutoriais gamificados e o design centrado no usuário. Revista GEMInIS, v. 6, n. 1, p. 62-78, 2015.

FORCELINI, F. et al. Avaliação do desconforto no uso de descascadores manuais por usuários com Artrite Reumatoide. In: MEDOLA, F. O. e PASCHOARELLI, L. C. (Ed.). Tecnologia Assistiva: Pesquisa e Conhecimento - I. 1. Bauru: Canal 6, 2018. cap. Tecnologias para Atividades da Vida Diária, p.215-224.

GIL, Antônio Carlos. Como elaborar projetos de pesquisa. São Paulo: Atlas, 2002.

GOELDNER, Isabela. et al. Artrite reumatoide: uma visão atual. Bras Patol Med Lab, v. 47, n. 5, p. 495-503, 2011

HARADA, F. J. B. et al. O Design Centrado No Humano aplicado: A utilização da abordagem em diferentes projetos e etapas do design. Revista D.: Design, Educação, Sociedade e Sustentabilidade, Porto Alegre, v. 8 n. 2, p. 87-107, 2016.

Instituto Brasileiro de Geografia Estatística - IBGE. Projeção da População 2018. Coordenação de População e Indicadores Sociais. Rio de Janeiro, 2018. Disponível em: <https://www. ibge.gov.br/apps/populacao/projecao/>. Acesso em: 20 ago. 2020.

KALBACH, James. Design de navegação web: otimizando a experiência do usuário. Porto Alegre: Bookman, 2009.

LEE, D. M., WEINBLATT M. E.: Rheumatoid Arthritis. The Lancet. v. 358, n. 9285, p. 903-911. 15 de set de 2001.

LIN, Yen-Ju; ANZAGHE, Martina; SCHÜLKE, Stefan. Update on the Pathomechanism, Diagnosis, and Treatment Options for Rheumatoid Arthritis. Cells, v. 9, n. 4, p. 880, 2020.

LITTLEJOHN, Emily A.; MONRAD, Seetha U. Early Diagnosis and Treatment of Rheumatoid Arthritis. Primary care, v. 45, n. 2, p. 237-255, 2018.

LOPES, Eliza Maura de Castilho. Significados e sentidos da deficiência adquirida em policiais militares. 2014. 125 f. Dissertação (mestrado) - Universidade Estadual Paulista Julio de Mesquita Filho, Faculdade de Ciências, 2014.

MOTA, L. M. H. et al. Diretrizes para o diagnóstico da artrite reumatoide. Rev Bras Reumatol, v. 53, n. 2, p. 141-157, 2013.

MYASOEDOVA, Elena et al. Is the incidence of rheumatoid arthritis rising?: results from Olmsted County, Minnesota, 1955-2007. Arthritis \& Rheumatism, v. 62, n. 6, p. 1576-1582, 2010. ORGANIZAÇÃO DAS NAÇÕES UNIDAS (ONU). Global Issues: Ageing. 2019. Disponível em: https://www.un.org/en/sections/issues-depth/ageing/. Acesso em: 24 ago. 2020.

OZENC, F. K. Modes of Transitions: Designing Interactive Products for Harmony and Wellbeing. Design Issues, v. 30, n. 2, p. 30-41, 2014. 
PAULA, P. M. S. Terapia ocupacional e tecnologia assistiva: funcionalidade para pessoas com artrite reumatoide. 2017. Dissertação (mestrado em Enfermagem) - Faculdade de Medicina de São José do Rio Preto, São José do Rio Preto, 2017.

Pesquisa Nacional de Saúde - PNS. 2013 - Ciclos de vida: Brasil e grandes regiões /IBGE, Coordenação de Trabalho e Rendimento. - Rio de Janeiro: IBGE, 2015.

PICHLER, Rosimeri Franck. USER-CAPACITY TOOLKIT: conjunto de ferramentas para guiar equipes multidisciplinares nas etapas de levantamento, organização e análise de dados em projetos de Tecnologia Assistiva. 2018. 310 f. Tese (Doutorado) - Curso de Design, Centro de Comunicação e Expressão, Universidade Federal de Santa Catarina, Florianópolis, 2018.

PINTO, A. H. et al. Capacidade funcional para atividade da vida diária de idosos da Estratégia de saúde da família da zona rural. Ciência \& Saúde Coletiva, v. 21, n. 11, 2016.

RIBEIRO, Luciana H. M.; NERI, Anita L. Exercícios físicos, força muscular e atividades de vida diária em mulheres idosas. Ciência \& Saúde Coletiva, v. 17, n. 8, p. 2169-2180, 2012.

SACKS, Jeffrey J.; LUO, Yao-Hua; HELMICK, Charles G. Prevalence of specific types of arthritis and other rheumatic conditions in the ambulatory health care system in the United States, 2001-2005. Arthritis care \& research, v. 62, n. 4, p. 460-464, 2010.

SANTOS F. C et. Al. Chronic pain in long-lived elderly: prevalence, characteristics, measurements and correlation with serum vitamin D level. Rev Dor. v. 16, n. 3, p 171-175, 2015.

SANTOS, Patrícia S. et al. Uso de dispositivos de assistência por indivíduo com osteoartrite de mãos/Use of assistive devices by individuals with hands osteoarthritis. Cadernos Brasileiros de Terapia Ocupacional, v. 26, n. 1, 2018.

SCHERER, F. DE V.; AZOLIN, B. R.; GUIMARÃES, F. C.; PAROLIN, G. Desenvolvimento de uma linha de mobiliário por meio de uma metodologia de design centrada no usuário. Design e Tecnologia, v. 7, n. 14, p. 135-146, 30 dez. 2017.

SENNA, E. R. et al. Prevalence of rheumatic diseases in Brazil: a study using the COPCORD approach. J Rheumatol, v. 31, n. 3, p. 594-7, 2004.

SILVA, Edna Lúcia da; MENEZES, Estera Muszkat. Metodologia da Pesquisa e Elaboração de Dissertação. Florianópolis: UFSC, 2005.

SILVA, Talita Silvério de Souza; MASSA, Lilian Dias Bernardo. A utilização de órteses de membro superior em pacientes com artrite reumatoide: uma revisão de literatura no campo da terapia ocupacional. Cad. Ter. Ocup. Ufscar, São Carlos, v. 23, n. 3, p.647-659, 2015. Disponível em: <http://dx.doi.org/10.4322/0104-4931.ctoAR0522>. Acesso em: 20 jun. 2018. SILVAGNI, Ettore et al. One year in review 2020: novelties in the treatment of rheumatoid arthritis. Clin Exp Rheumatol, v. 38, p. 181-94, 2020.

SMOLEN, J. S.; ALETAHA, D.; MCINNES, I. B. Rheumatoid arthritis. Lancet Lond Engl 388: 2023-2038. 2016.

SOCIEDADE BRASILEIRA DE REUMATOLOGIA (São Paulo). Artrite Reumatoide. 2018. Disponível em:<https://www.reumatologia.org.br/doencas/principais-doencas/artrite-reumatoide/>. Acesso em: 24 mai. 2018.

Recebido: 20 de dezembro de 2019. Aprovado: 24 de agosto de 2020. 